\title{
Policy Regarding the Sequential Lineup Is Not Informed by Probative Value but Is Informed by Receiver Operating Characteristic Analysis
}

Current Directions in Psychological Science

2014, Vol. 23(1) 17-18

(C) The Author(s) 2014

Reprints and permissions:

sagepub.com/journalsPermissions.nav

DOI: $10.1177 / 0963721413510934$

cdps.sagepub.com

(S)AGE

\author{
John T. Wixted ${ }^{1}$, Scott D. Gronlund ${ }^{2}$, and Laura Mickes ${ }^{3}$ \\ ${ }^{1}$ University of California, San Diego; ${ }^{2}$ University of Oklahoma; and ${ }^{3}$ Royal Holloway, University \\ of London
}

\begin{abstract}
It is important to determine if switching from simultaneous to sequential lineups affects response bias (the inclination to make an identification from a lineup), discriminability (the ability to distinguish between innocent and guilty suspects), or both. Measures of probative value cannot provide such information; receiver operating characteristic analysis can. Recent receiver operating characteristic analyses indicate that switching to sequential lineups both induces more conservative responding and makes it more difficult to distinguish between innocent and guilty suspects. If more conservative responding is preferred (i.e., if policymakers judge that the harm associated with the reduction of correct identifications is exceeded by the benefit associated with the reduction in false identifications), recent data indicate that this result can be achieved without a loss of discriminability by using the simultaneous lineup procedure in conjunction with a more conservative decision criterion.
\end{abstract}

\section{Keywords}

eyewitness memory, simultaneous versus sequential lineups, signal detection theory

Wells (2014, this issue) wrote, "For eyewitness-identification evidence, probative value is reflected in likelihood ratios or probabilities that an identification of the defendant offered at trial was accurate or mistaken" (p. 11). Figure 1 presents hypothetical receiver operating characteristic (ROC) data that show the full range of correct and false identification rates associated with a simultaneous lineup and, separately, a sequential lineup. Next to each ROC point is a common measure of probative value. When Wells referred to probative value, he was referring only to the right-most ROC point for each procedure. In Figure 1, the probative value of the right-most ROC point is higher for the sequential lineup (7.4) than for the simultaneous lineup (6.9). Wells argued that a result like this means that an identification made using the sequential procedure is more trustworthy than is one made using the simultaneous procedure. But this conclusion applies only to situations in which confidence is ignored. Wells ignored confidence but courts of law do not, and neither should researchers who want to determine which lineup procedure is associated with more trustworthy identifications.
Just as a higher (i.e., more conservative) criterion may be used in a court of law by attaching less weight to lowconfidence identifications, one can do the same with data collected in the laboratory. The use of a slightly more conservative criterion, which is achieved by treating the lowest-confidence identifications as effective nonidentifications, generates the next point to the left on the ROC. For both procedures, this new ROC point is associated with a higher probative value than its neighbor to the right. The use of an ever more conservative criterion generates additional points to the left on the ROC, each of which is associated with a higher probative value than the last. It is not known which ROC point is the most relevant to a court of law, nor which probative value, but it seems certain that the right-most point (which includes low-confidence identifications) is the least relevant.

Corresponding Author:

John T. Wixted, Department of Psychology, University of California, San Diego, La Jolla, CA 92093

E-mail: jwixted@ucsd.edu 


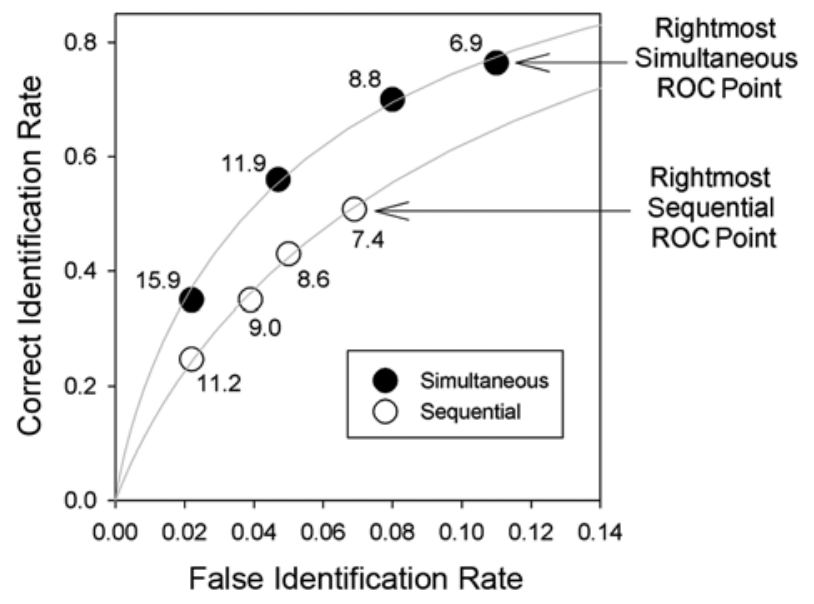

Fig. 1. Hypothetical simultaneous and sequential receiver operating characteristics (ROCs), with probative values (correct identification rate/false identification rate) indicated next to each data point. The right-most ROC point represents the overall correct and false identification rates that are typically analyzed in an eyewitness memory study.

Instead of using a measure of probative value to identify the best lineup procedure, one should ask which lineup procedure is better able to discriminate between innocent and guilty suspects. The use of $d^{\prime}$ to measure discriminability is conceptually the right approach, but, in the case of lineups, that measure is directly tied to questionable and untested theoretical assumptions. ROC analysis measures discriminability without recourse to theory, which is why it has long been used in medicine to measure how well a diagnostic test discriminates between the presence or absence of a disease.

Wells's (2014) observation that we "were correct to suggest that receiver operating characteristic analyses are the best way to determine if the simultaneous/sequential difference is a criterion shift" (p. 14) missed the main point of our article (Gronlund, Wixted, \& Mickes, 2014, this issue). The most important function of ROC analysis is to identify the procedure that yields higher discriminability. Just as we have illustrated in Figure 1 with hypothetical data, the first three published studies using ROC analysis found that simultaneous lineups yield significantly higher discriminability than sequential lineups (Dobolyi \& Dodson, in press; Gronlund et al., 2012; Mickes, Flowe, \& Wixted, 2012). If that turns out to be the final story, it would mean that any probative-value gain that might be achieved from the conservative criterion induced by a sequential lineup could be exceeded by using a suitably conservative criterion in conjunction with a simultaneous lineup. ${ }^{1}$ That approach maximizes discriminability, which is the only way to simultaneously reduce both errors to which Wells referred-mistaken identifications of the innocent and nonidentifications of the guilty.

\section{Recommended Reading}

Green, D. M., \& Swets, J. A. (1966). Signal detection theory and psychophysics. New York, NY: Wiley. The original signal detection classic, providing a mathematically elegant (and still timely) treatment of topics such as receiver operating characteristic analysis, decision goals, and the theory of ideal observers.

Macmillan, N. A., \& Creelman, C. D. (2005). Detection theory: A user's guide (2nd ed.). Mahwah, NJ: Erlbaum. The modern classic, providing a more accessible treatment of how signal detection theory applies to the many kinds of experimental designs that are routinely used by psychologists to study memory and perception.

\section{Author Contributions}

All authors contributed equally to the manuscript.

\section{Declaration of Conflicting Interests}

The authors declared that they had no conflicts of interest with respect to their authorship or the publication of this article.

\section{Note}

1. Ideally, the confidence statement used to establish an acceptable criterion would be the one that was made at the time of the initial identification, not the one made later during a trial (Technical Working Group for Eyewitness Evidence, 1999).

\section{References}

Dobolyi, D. G., \& Dodson, C. S. (in press). Eyewitness confidence in simultaneous and sequential lineups: A criterion shift account for sequential mistaken identification overconfidence. Journal of Experimental Psychology: Applied.

Gronlund, S. D., Carlson, C. A., Neuschatz, J. S., Goodsell, C. A., Wetmore, S. A., Wooten, A., \& Graham, M. (2012). Showups versus lineups: An evaluation using ROC analysis. Journal of Applied Research in Memory and Cognition, 1, 221-228.

Gronlund, S. D., Wixted, J. T., \& Mickes, L. (2014). Evaluating eyewitness identification procedures using ROC analyses. Current Directions in Psychological Science, 23, 3-10.

Mickes, L., Flowe, H. D., \& Wixted, J. T. (2012). Receiver operating characteristic analysis of eyewitness memory: Comparing the diagnostic accuracy of simultaneous and sequential lineups. Journal of Experimental Psychology: Applied, 18, 361-376.

Technical Working Group for Eyewitness Evidence. (1999). Eyewitness evidence: A guide for law enforcement. Washington, DC: U.S. Department of Justice, Office of Justice Programs.

Wells, G. L. (2014). Eyewitness identification: Probative value, criterion shifts, and policy regarding the sequential lineup. Current Directions in Psychological Science, 23, 11-16. 